\title{
In sight, out of mind: The role of eye movements in the rapid resumption of visual search
}

\author{
WiEske van Zoest \\ University of British Columbia, Vancouver, British Columbia, Canada \\ Alejandro Lleras \\ University of Illinois at Urbana-Champaign, Urbana, Illinois \\ AND \\ Alan Kingstone ANd James T. EnNS \\ University of British Columbia, Vancouver, British Columbia, Canada
}

\begin{abstract}
Three experiments investigated the role of eye movements in the rapid resumption of an interrupted search. Passive monitoring of eye position in Experiment 1 showed that rapid resumption was associated with a short distance between the eye and the target on the next-to-last look before target detection. Experiments 2 and 3 used two different methods for presenting the target to the point of eye fixation on some trials. If eye position alone is predictive, rapid resumption should increase when the target is near fixation. The results showed that gaze-contingent targets increased overall search success, but that the proportion of rapid responses decreased dramatically. We conclude that rather than depending on a high-quality single look at a search target, rapid resumption of search depends on two glances; a first glance in which a hypothesis is formed, and a second glance in which the hypothesis is confirmed.
\end{abstract}

Imagine you are looking for your favorite can of soup in the supermarket and, before you find it, someone walks in front of you, momentarily blocking your view. Based on the results of a recent study, you will likely benefit from even a $100-\mathrm{msec}$ glance at the shelves when you resume looking for your soup after the interruption. Specifically, Lleras, Rensink, and Enns (2005) found that humans resume an interrupted search much more quickly than they are able to begin a new search.

Lleras et al. (2005) presented participants with a modified search task in which participants were presented with only brief glimpses of the search display ("look" times were typically around $100 \mathrm{msec}$ ). Observers were required to report the color of a target rotated $\mathrm{T}$ shape presented among rotated $\mathrm{L}$ shapes. The presentation of the search display was followed by blank screens of longer durations of around $900 \mathrm{msec}$. Search and blank displays were alternatively presented until the observer responded to the identity of the target. The results showed that in $75 \%$ of all trials, participants were able to correctly identify the target within three presentations of the search display. Moreover, the results showed that successful responses to the second and subsequent search displays occurred much earlier in time than the responses elicited following the first initial search display. Following second and subsequent displays, participants often showed extremely short response laten- cies to target identification (below $400 \mathrm{msec}$.), a finding Lleras et al. (2005) referred to as rapid resumption.

It was argued that the ability of observers to rapidly resume an interrupted search is the result of target relevant preprocessing of the display in earlier looks (Lleras et al., 2005). In brief, based on the available information in first presentation of the search display, observers form a perceptual hypothesis regarding the relevant target features. The results are consistent with the perceptual hypothesis including information specific to the response required of the target (i.e., only task-relevant target features are represented) (Lleras, Rensink, \& Enns, 2007). In order to confirm the hypothesis, one additional look is required to match the perceptual hypothesis with incoming sensory information. Rapid resumption occurs because a hypothesis based on a previous glance can be tested very rapidly in a subsequent glance, given that the initial hypothesisgeneration step has already been performed. The finding that people are able to rapidly resume search points to an important role for memory in visual search (Lleras et al., 2005, 2007).

However, there is an alternative explanation that does not appeal to any memory processes. Perhaps the rapid resumption effect is an artifact of simply finding a target close to where the eye is currently fixated, with the high spatial and color resolution of the fovea permitting target

W. van Zoest, wieske@psych.ubc.ca 
identification in less time than when the target appears more eccentrically. If so, then rapid resumption should be more likely when the eyes are near the target in a search display, rather than reflecting any memorial process. Eye movements and eye position were not recorded in Lleras et al. (2005), leaving open the possibility that although the eye was generally far away from the target on the first look at the display, when the search display reappeared after an interruption, the eyes were fixated near the target on responses categorized as rapid resumption.

In support of this account, several authors have argued that visual search does not require memory for the items in a search display (Horowitz \& Wolfe, 1998, 2001; Woodman, Vogel, \& Luck, 2001). Specifically, Horowitz and Wolfe (1998) argued that visual search relies on a moment-to-moment representation of the environment and so does not keep track of which items have already been examined. Their study compared search efficiency under two different conditions: static and dynamic search. Search in the static condition was for a rotated letter T among rotated letters $\mathrm{L}$ in an unchanging display. In the dynamic condition, the letters were relocated every $111 \mathrm{msec}$, making it impossible to keep track of the progress of search. It was reasoned that if memory contributes significantly to search efficiency, then search should be less efficient in the dynamic than in the static condition. Nevertheless, and surprisingly so, the efficiency of search did not differ between conditions. Horowitz and Wolfe concluded that the visual system does not accumulate information about object identity over time during a search (however, see Kristjansson, 2000; von Mühlenen, Müller, \& Müller, 2003).

Others have argued in support of memorial guidance in visual search (Beck, Peterson, \& Vomela, 2006; Chun \& Jiang, 1998, 2003; Chun \& Nakayama, 2000; Klein \& MacInnes, 1999; Kristjansson, 2000; Oh \& Kim, 2004; Peterson, Kramer, Wang, Irwin, \& McCarley, 2001). For example, Chun and Jiang (1998) reported that memory for visual context can guide spatial attention. In this study, observers performed a visual search for targets appearing among distractor stimuli arrayed in repeated or new spatial configurations. The results showed that targets presented in repeated visual search stimulus configurations were detected more quickly than targets presented in new visual search stimulus configurations. It was concluded that visual context of a target is incidentally learned during visual search, forming a memory for context which guides attention toward target locations in subsequent encounters. Furthermore, it was shown that these representations of the visual context of a target affected performance without explicit awareness or recognition of the contextual cues. Whereas observers were faster to respond to repeated displays, they could not explicitly distinguish a repeated context from a new configuration (Chun \& Jiang, 2003; Jiang, Song, \& Rigas, 2005). Furthermore, in line with the finding of rapid resumption of visual search, Chun and Nakayama (2000) have suggested that contextual cuing may facilitate interactions with a given scene in the environment, sampled intermittently as one looks away and back over short times scales of a few seconds.
Additional support for memory in search has come from studies measuring eye movements (Dickinson \& Zelinsky, 2005; Henderson \& Hollingworth, 2003; Irwin \& Gordon, 1998; McCarley, Wang, Kramer, Irwin, \& Peterson, 2003; Peterson et al., 2001). For example, McCarley et al. employed a gaze-contingent search paradigm to examine properties of memory for items or locations in a display that have already been inspected. In this search paradigm, a few items were revealed at a time in a temporal stream. After each fixation, observers were presented a pair of potential saccade targets. One of these targets was a new item presented at a location that had not yet been revealed, and the other was an old item that had been presented earlier in the trial. It was predicted that preferential selection of the new item as the saccade target provides evidence of memory having inspected the old item. The results indicated that for as many as three to four fixations following inspection of a given item, observers were more likely to fixate a new object at a different location than to re-inspect an old item (McCarley et al., 2003). Furthermore, memory for inspected locations was evidenced even for stimuli that disappeared after presentation, suggesting that traces for inspected locations existed even when no objects were present on the screen. These results suggest that oculomotor selection is guided by memory in visual search.

In the present study, we investigated the role of eye movements in the rapid resumption of search. Eye movements provide a direct method to access the allocation of attention (Deubel \& Schneider, 1996; Hoffman \& Subramaniam, 1995; Kowler, Anderson, Dosher, \& Blaser, 1995; Schneider \& Deubel, 1995; Shepherd, Findley, \& Hockey, 1986) and have been shown to be directed related to spatial memory (Brockmole \& Henderson, 2006; Lawrence, Myerson, \& Abrams, 2004; McPeek, Maljkovic, \& Nakayama, 1999; Postle, Idzikowski, Sala, Logie, \& Baddeley, 2006; Theeuwes, Olivers, \& Chizk, 2005). Eye movements allow us to explore the relation between oculomotor selection and memory in interrupted visual search. In addition, eye movements allow us to directly test the hypothesis that, instead of reflecting memory processes, the rapid resumption effect is an artifact of finding a target close to where the eye is currently fixated. When the search display returns to view following an interruption, the eyes may be fixated right where the target was located. As such, it may be target location relative to fixation that is the critical factor in rapid resumption. Thus, investigating eye position during interrupted search will provide insight into what extent foveal viewing of the target contributes to rapid resumption. Moreover, if foveal viewing proves essential, having a measure of eye position in each look prior to responding allows us to investigate in which look a foveal view of the target is most important for rapid resumption of search. Finding that a foveal view of the target is most important only in the final look before a response supports the idea that rapid resumption may depend on a single high-quality look; thereby, undermining the importance of target preprocessing in the next-to-last look in rapid resumption. Finding that a foveal view of the target is most important in the next-to-last look supports the propo- 


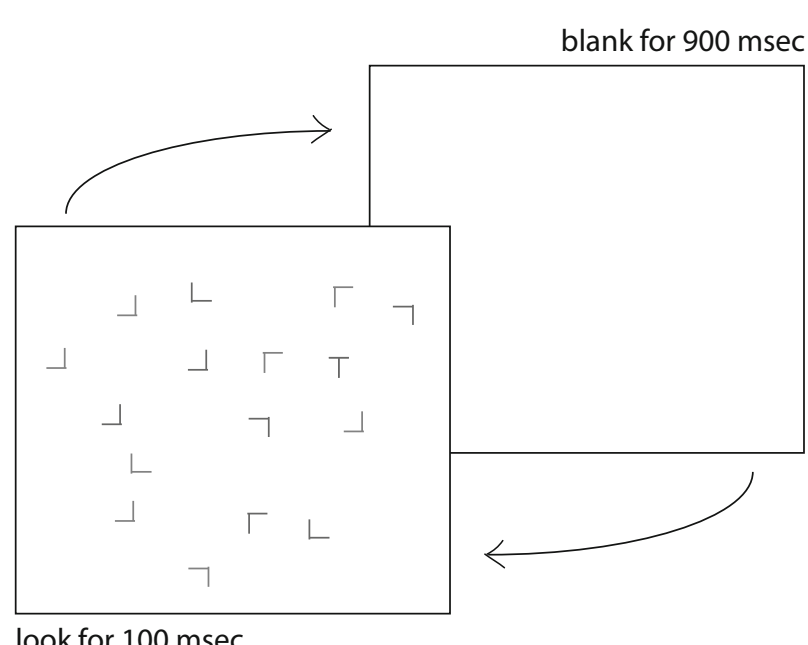

look for $100 \mathrm{msec}$

Figure 1. Schematic depiction of the interrupted visual search task.

sition that rapid resumption relies on hypothesis formation in the penultimate look, hinting at the importance of some form of memory for the target from one look to the next.

In Experiment 1, we passively recorded eye movements during an interrupted search experiment. The response time (RT) results replicated the finding that participants were much faster to resume search than they were to initiate a search. The eye movement recordings revealed that rapid resumption was more likely when the eyes were near the target location. In Experiments 2 and 3, we used gazecontingent target presentations as a tool to distinguish between the roles played by target location on the eye and the need for hypothesis formation in rapid resumption. The results showed that when the target was presented directly to the fovea, overall search success increased sharply during the next 1,000 msec. Yet at the same time, the proportion of correct responses occurring during the first $500 \mathrm{msec}$ decreased dramatically for these gaze-contingent presentations of the target. We conclude that rather than depending on a high-quality single look at a search target, rapid resumption of search depends on two glances; a first glance in which a hypothesis is formed, and a second glance in which the hypothesis is confirmed.

\section{EXPERIMENT 1 Eye Movements During Interrupted Search}

In Experiment 1, participants performed a search task that was identical to the modified search task reported in Lleras et al. (2005). Presentation of a standard visual search display for $100 \mathrm{msec}$ (called a look) was interrupted by the presentation of blank displays for $900 \mathrm{msec}$ (called a blank). The term epoch will be used to refer to one cycle of look and blank (Rensink, 2000). Eye movements were monitored continuously while participants performed this task.

If rapid resumption depends on the eyes being fixated near the target location, we expect that the distance of the eye from the target on the last look prior the response will be smaller on trials where observers are quick to respond (i.e., RT within $500 \mathrm{msec}$ of search display onset, normalized so that the responses in each epoch sum to $100 \%$ ) than in the trials where observers are slow to respond (i.e., normalized RT more than $500 \mathrm{msec}$ following search display onset). If rapid resumption depends on the formation of a perceptual hypothesis in one look that requires confirmation on a next look, it is predicted that rapid resumption occurs when the eye was positioned near the target for two looks in succession. In this case, a near target fixation in the next-tolast look may predict the likelihood of a rapid resumption response better than a near fixation in the final look.

\section{Method}

Participants. Sixteen students of the University of British Columbia participated as paid volunteers in one 60 -min session. All reported having normal or corrected-to-normal vision. Two people were omitted from the analysis due to poor accuracy (total of $>20 \%$ incorrect responses) resulting in a total of 14 participants.

Apparatus. An Intel Pentium III processor controlled the timing of the events and generated stimuli. Stimuli were displayed on a 17 -in. SVGA color monitor (Samsum SyncMaster 753df); resolution was $1,024 \times 768$ pixels at $85-\mathrm{Hz}$ refreshing rate. Eye movements were recorded by means of an Eyelink I tracker (SR Research Ltd., Mississauga, Ontario, Canada) with a $250-\mathrm{Hz}$ temporal resolution and a $0.2^{\circ}$ spatial resolution. The system uses an infrared videobased tracking technology to compute the pupil center and pupil size of both eyes. An infrared head motion tracking system was also used. Saccades were identified by means of a velocity threshold $\left(35^{\circ} / \mathrm{sec}\right)$ and an acceleration threshold $\left(9,500^{\circ} / \mathrm{sec}^{2}\right)$. All subjects were tested in a dark room with their heads resting on a chinrest. The monitor was located at eye level $53 \mathrm{~cm}$ from the chinrest.

Stimuli. One target T-shape was presented among fifteen nontarget L-shapes. Each item was presented in one of four randomly selected orientations and items subtended $0.54^{\circ}$ of visual angle. Items were randomly presented on an invisible $6 \times 6$ grid (cell size $=$ $\left.4.0^{\circ} \times 3.2^{\circ}\right)$, with a random jitter of $\left( \pm 0.45^{\circ}\right)$ to avoid the collinear alignment of items. Letters were blue or red, and there were always an equal number of red and blue items presented in the display.

Design and Procedure. A within-subjects design was used. Participants were required to report the color of a target T-shape (either red or blue), presented among other L-shapes (either red or blue). Participants pressed the "/" key for a red target T-shape and the "z" key for a blue target T-shape.

Eye movements were passively monitored during the experiment. Prior to the recording, participants viewed a calibration display consisting of nine points in a square array, which were fixated sequentially. The eye-tracking system was calibrated at the start of the experiment and following each block. In order to start each trial participants maintained fixation on a central $\operatorname{dot}\left(0.25^{\circ}\right)$. Participants then pressed the space bar in order to apply a drift correction and to begin the trial with the presentation of a small fixation point $\left(0.1^{\circ}\right)$ for $500 \mathrm{msec}$. The search display was presented for $100 \mathrm{msec}$ and interrupted by blank displays of $900 \mathrm{msec}$. See Figure 1. A maximum of 16 epochs were presented. Trials were terminated as soon as the participant responded or after $16 \mathrm{sec}$, whichever occurred first.

To make sure that participants understood the task correctly, participants were given both written and oral instruction. Participants were told their eye movements would be passively monitored during the experiment. Participants first completed 30 practice trials, followed by 300 experimental trials divided in two blocks of 150 . Feedback concerning response accuracy was provided every 30 trials.

\section{Results}

Incorrect responses ( $5.19 \%$ of trials) and reaction times higher than $10,000 \mathrm{msec}(0.76 \%$ of trials $)$ were counted 
as errors and were excluded from the analyses. Trials in which the eyes moved away from the fixation point prior to the presentation of the first search display $(3.10 \%$ of trials) were also counted as errors and were not analyzed further.

Manual response. RT is measured from the onset of the first look; normalized RT is measured from the onset of each look-that is, computed for responses that are made within a given epoch. Figure 2 shows the normalized distribution of correct responses. After just one look, participants were able to correctly identify the target in $17 \%$ of trials. The majority of these responses were elicited in the second half of the distribution - that is, after $500 \mathrm{msec}$ (only $5.5 \%$ of the responses in the first epoch were faster than $500 \mathrm{msec}$ ). In contrast, in the second epoch, $41 \%$ of responses in this epoch occurred within the first $500 \mathrm{msec}$; in the third epoch, $37 \%$ of the responses occurred within $500 \mathrm{msec}$.

The distribution of RT in Epoch 1 was compared with a normalized RT distribution of Epochs 2-6. Participants responded in a fundamentally different way to the first display than to all subsequent displays $\left[\chi^{2}(9,3337)=\right.$ $250.50, p<.001$, Cramer's $V=0.27$ ] (comparison across ten 100 -msec bins). Specifically, they were able to complete a search much faster if they had a previous look at the display.

Eye movement data. The first question we examined was whether rapid resumption varied depending on the location of the target relative to the initial eye position. Since each trial began with the eyes fixated at the center of the screen, we compared RT distributions for displays in which the target was contained within a central $5^{\circ}$ radius with displays in which the target lay beyond that radius $\left(5^{\circ}\right.$ is less than the average distance between items in the display). Data for these two conditions are shown in Figure 3 and they reveal three important findings. First, RT distributions for the first epoch in Figure 3A show that search success is much greater overall when the target is within $5^{\circ}$ of fixation $(60.6 \%$ [241/398 trials] of correct responses) than outside it $(10.6 \%$ [313/2,940 trials] of correct responses) $\left[\chi^{2}(3,338)=630.7, p<.0001\right.$, Cramer's $V=0.435]$. Second, normalized RT distributions of the first epoch in Figure 3B show that targets near fixation do not contribute to a greater proportion of rapid responses (within $500 \mathrm{msec}$ ) in the first look than targets that are more distant. The small significant difference here is due entirely to the fifth bin $\left[\chi^{2}(554)=5.788, p<.05\right.$, Cramer's $V=0.102]$. Third, Figure $3 \mathrm{C}$ shows that it is the second look for a target near fixation that yields the highest proportion of rapid resumption responses, $73.9 \%$ (68/92), in comparison with 37.2\% (326/830) on Epoch 2 for distant target displays $\left[\chi^{2}(617)=43.1605, p<.0001\right.$, Cramer's $V=0.264]$.

For more detailed questions concerning the relation between target distance from the fovea and the rapid resumption effect, manual responses were sorted according to whether participants were able to rapidly resume search as compared to when they responded more slowly. Normalized RT responses that occurred between 0 and $500 \mathrm{msec}$ following search display presentation were taken to rep- resent rapid resumption (RR) responses, whereas normalized responses that occur between 501 and 1,000 msec are taken to represent normal search (NS) responses. The distance from the fovea to the target location was computed for each of these response classes on the three looks prior to the successful response (look-2, look-1, look), as shown in Figure 4.

These data pointed to three main findings. First, the distance between the fovea and the target decreased with look, indicating that target detection occurred once the eyes were on average within about $3^{\circ}$ of the target. Second, the eyes tended to be closer to the target prior to RR than to NS responses. Third, the largest difference in target proximity that favored RR responses occurred on the look just prior to the look eliciting the response (look-1). These observations were supported by an ANOVA examining the factors of look (look-2, look-1, and look) and response type (RR vs. NS) on foveal distance from the target. It revealed a main effect of look $[F(2,26)=376.77, p<$ $.001]$, a main effect of response $[F(1,13)=170.54, p<$ $.01]$, as well as an interaction between look and response $[F(2,26)=34.44, p<.01]$. In order to clarify this interaction between look and response type, Tukey HSD post hoc comparisons were computed on the difference score in eye-fixation-to-target distance between RR and NS responses. These showed that the difference in distance between the RR and NS responses was significantly larger in look-1 than in look-2 or look (both $p$ s $<.001$ ).

In addition, the results revealed that in the next-tolast look, fixation duration was higher for RR responses than for NS. While fixation duration did not change from look-1 to look for RR responses, it did significantly change across looks in NS responses. An ANOVA was conducted on fixation duration with look (look-1 and look) and response type (RR vs. NS) as factors. A main effect of look was found, indicating that the eyes were fixated longer on the last look prior to the response $(658 \mathrm{msec})$ than on look-1 $(617 \mathrm{msec})[F(1,13)=11.728, p<.01]$. The effect of response type was marginally significant $[F(1,13)=$ $3.25, p=.09]$, indicating that fixation duration was slightly higher in NS trials $(642 \mathrm{msec})$ than in RR trials (634 msec). Most importantly, the interaction between look (look-1, look) and the type of search response (RR, NS) was significant $[F(1,13)=12.44, p<.01]$. Post hoc comparisons (Tukey HSD tests) revealed that fixation duration was higher for RR responses than for NS responses in look-1 $(p<.05)$; in the final look, however, the comparison between the RR and NS responses was not significant $(p>.1)$. Moreover, fixation duration did not significantly vary between look and look-1 in the RR trials $(p>.5)$ but did significantly change as a function of looks in NS trials $(p<.05)$. RR responses were associated with similar duration fixations on look-1 and on look (634 and $633 \mathrm{msec}$, respectively) whereas NS responses were associated with shorter fixations on look-1 and longer fixations on look (601 and $684 \mathrm{msec}$, respectively).

\section{Discussion}

The distribution of the correct manual responses showed that participants were able to complete a search 

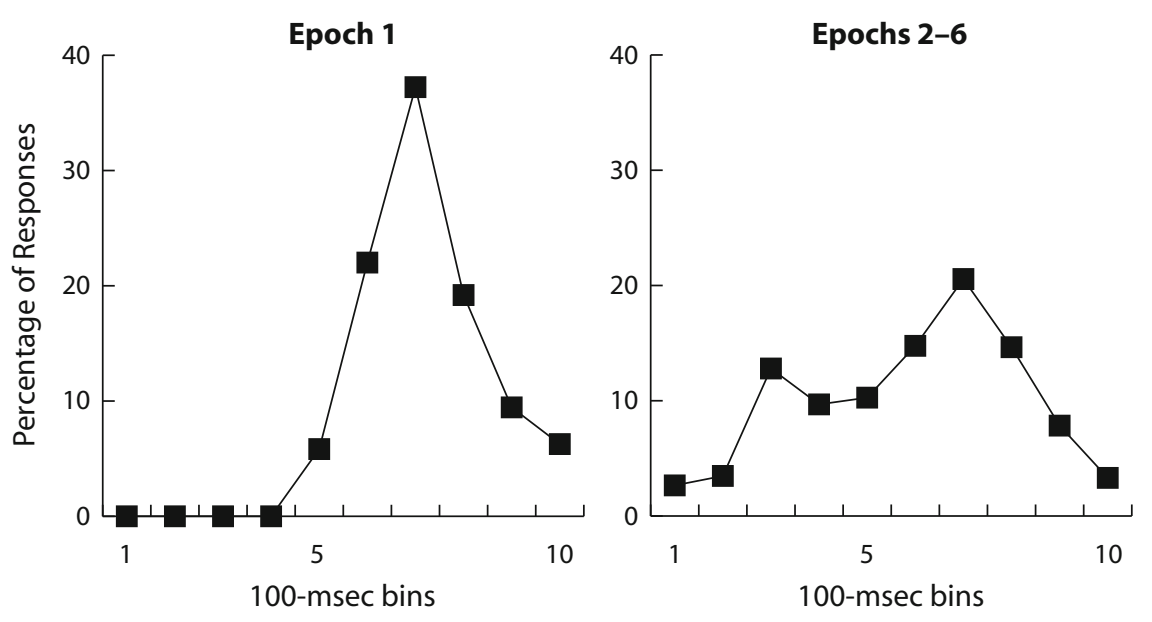

Figure 2. Correct response time (RT) distributions in Epoch 1 and in Epochs 2 through 6 in Experiment 1, normalized so that the responses in each epoch sum to $100 \%$.
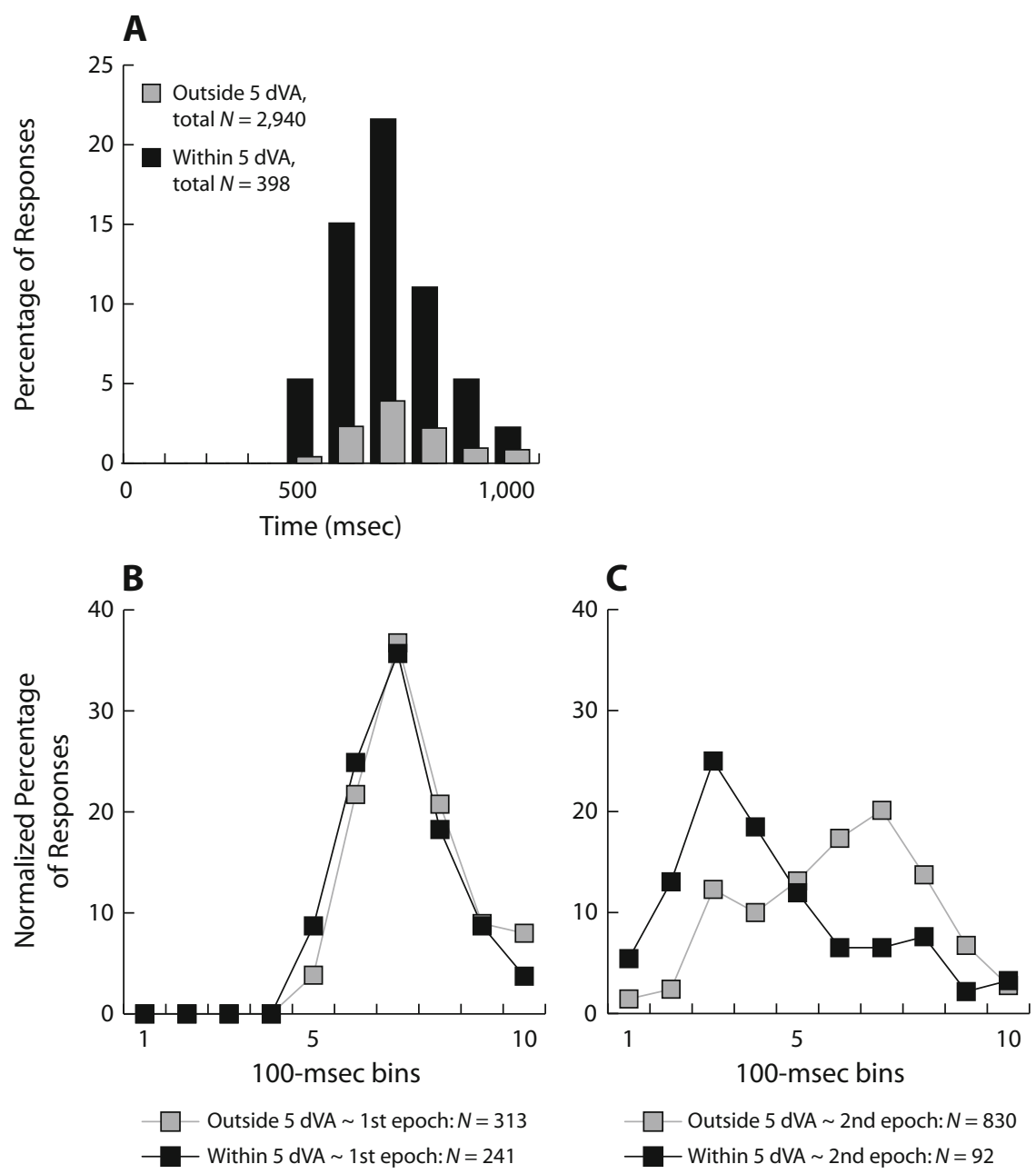

Figure 3. Illustration of the effect of eccentricity in interrupted search in Experiment 1. RT distribution for the first epoch for displays in which the target was presented within and outside a $5^{\circ}$ radius of the fixation point at the center of the screen (A). Normalized RT distribution for correct responses for Epoch 1 (B) and Epoch 2 (C) for targets presented within and outside a $5^{\circ}$ radius of the fixation point at the center of the screen. dVA, degrees of visual angle. 
much faster if they had a prior look at the display: Correct RTs were faster on second and subsequent search displays than on the first look at the display. This replicates the main finding of Lleras et al. (2005).

Recordings of eye position during this search task indicated that the distance from fovea to target decreased as a function of look. Whereas three looks before observers responded, the eyes were fixated about $13.5^{\circ}$ away from the target, two looks before the response the eyes were fixated closer to the target at $9.5^{\circ}$. The eyes where fixated closest to the target on the last look prior to the response, at $3^{\circ}$.

In addition, the eye position data showed that proximity of the fovea and the target was a strong predictor of success. Targets that lay near fixation on the first look at a display, as well as those that lay near fixations on subsequent looks, were much more likely to be identified correctly within $1,000 \mathrm{msec}$ than targets that were distant. However, the distance between fovea and target did not in itself predict the rapid resumption of search (correct responses within $500 \mathrm{msec}$ of display onset). For this to occur, the eye had to be near the target for two looks in succession, with a near target fixation in the next-to-last look predicting this effect more strongly than a near fixation in the final look.

The fovea was also closer to the target on those trials where observers were quick to resume search as compared to the trials where observers were slower to respond. This is consistent with the possibility that rapid resumption is an artifact of eye position. An eye position that is near the target when the search display reappears may allow participants to respond to it more quickly.

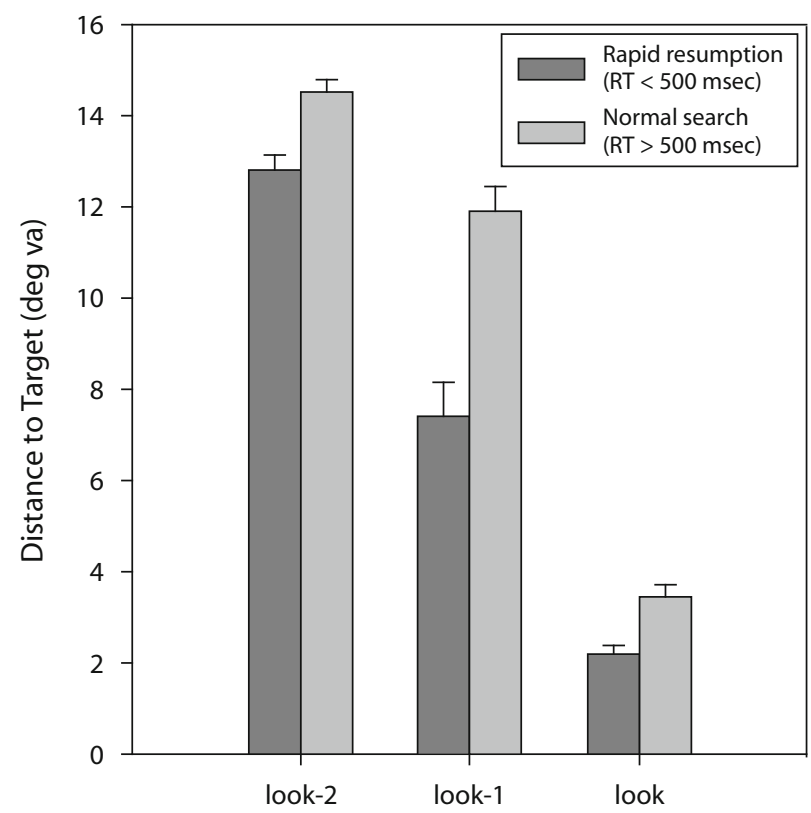

Figure 4. The distance in degrees of visual angle between the current eye position and the target in look-2, look-1, and the final look before the response for normalized RR and NS responses.
Yet the results of Experiment 1 also provide evidence for the idea that rapid resumption is based on target preprocessing and hypothesis formation in the penultimate look. A close look at the fovea-target distance on RR and NS trials shows that the difference in this measure for these two types of responses is larger in look-1 than in the final look. If rapid responding is solely an artifact of eye position, we would expect to see a main effect of look, with the fovea-target distance decreasing to the final look, and a main effect of response type, with the fovea-target distance being smaller for RR trials. If anything the difference in distance between the RR and NS responses might be expected to be largest on the final look. Yet the data show it is largest in the second-to-last look.

This interaction between look and response type can be explained by the perceptual hypothesis account. If a perceptual hypothesis of the target is formed on the basis of the second-to-last look (i.e., look-1), then it should also be the glance that is the best predictor of rapid resumption. Of course, the final look would also likely have a close fovea-target distance, because it is in that look that the perceptual hypothesis is confirmed. But critically, the perceptual hypothesis account predicts that the fovea-target distance should be relatively small on two consecutive looks. Moreover, the interaction found between the RR and NS responses in fixation duration support the perceptual hypothesis account. Specifically, these results showed that in the next-to-last look, fixation duration was higher for RR responses than for NS. Accordingly, a longer and better glance in the next-to-last look allowed participants to respond faster in the final look. As such, processing in the next-to-last look may be the best predictor of rapid resumption. Experiment 2 investigates this possibility by artificially influencing the distance between the fovea and the target during an interrupted search.

\section{EXPERIMENT 2 Gaze-Contingent Target Presentations}

In Experiment 2, we used gaze-contingent target presentations to ensure that the target was presented near the fovea on a random one-half of all trials. If rapid resumption depends strictly on the eyes being close to the target in the final look, then the percentage of rapid resumption responses should increase immediately following a look in which the target is presented to the fovea. On the other hand, if rapid resumption depends on the confirmation of a perceptual hypothesis, then the fovea would have to be near the target on two consecutive looks. The prediction of the perceptual hypothesis account is therefore that presenting the target to the fovea for a single look will not increase the percentage of rapid responses. Moreover, relocating the target in order to present it to the fovea will likely interfere with efficient search since the target location will no longer match any perceptual hypothesis formed in the previous look. Since direct confirmation of the current hypothesis will no longer be possible, a new time-consuming hypothesis will need to be created and confirmed, slowing search. 


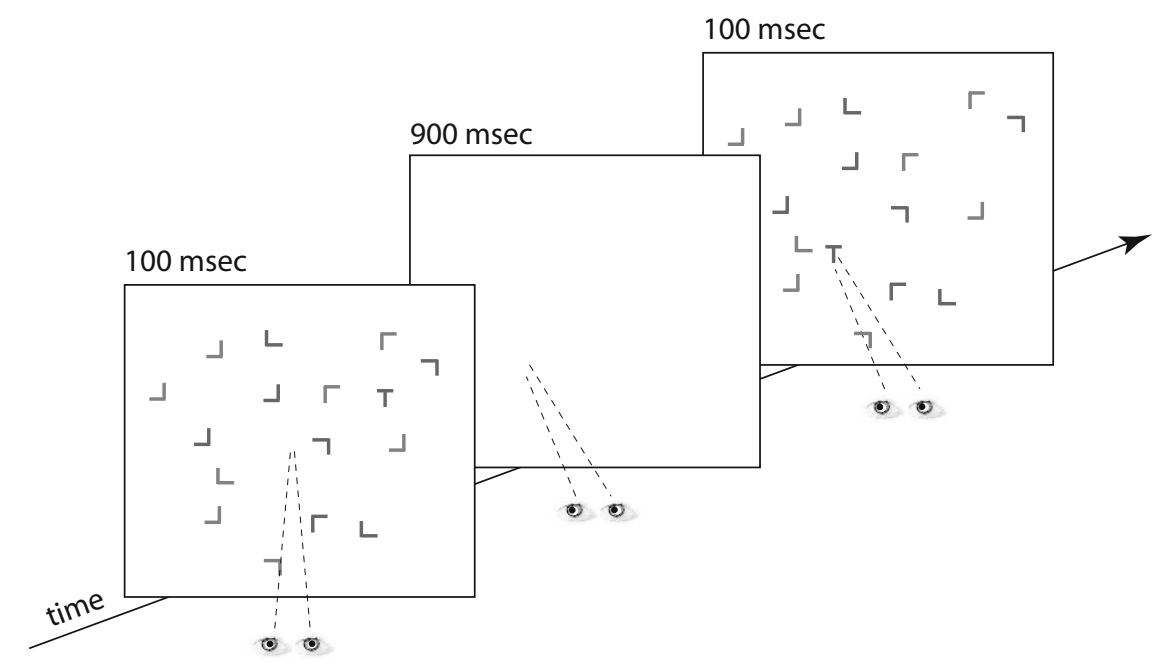

Figure 5. Example of gaze-contingent presentation in Experiment 2. The target was presented where the eyes were located at the reappearance of the search display in second and subsequent looks.

\begin{abstract}
Method
Participants. Twelve students of the University of British Columbia participated for course-credit in one 60 -min session. All reported having normal or corrected-to-normal vision.

Apparatus and Stimuli. The apparatus and stimuli were identical to those in Experiment 1.

Design and Procedure. The design was similar to that in Experiment 1 , except for that a contingent gaze paradigm was used to present the target at eye fixation in half of all trials $(50 \%)$. In the remaining $50 \%$ of the trials, no contingent eye programming was employed and thus these trials constituted as standard search trial (i.e., identical to the trials in Experiment 1). In the contingent target presentation condition, the target was presented where the eyes were located at the reappearance of the search display. The target was present always, but because the eyes were fixated at the fixation-point at the center of the screen at the start of the trial (i.e., first look) the target was presented contingent to eye fixation in the second and subsequent looks only. The target was consistently presented at eye fixation in each look until the participant made a response. See Figure 5.

To prevent the target being presented at the location of a nontarget, if the eyes happened to fixate within $1^{\circ}$ of a nontarget, the target was reallocated $0.85^{\circ}$ away from the location of the nontarget. In case of the target was reallocated, the target was still presented at $.85^{\circ}$ of eye fixation.

The instructions given to the participants were identical to those in Experiment 1. Participants were told that their eyes would be passively monitored; participants were not informed of the contingent target presentation. Participants first completed 32 practice trials, followed by 360 experimental trials divided in three blocks of 120 . Feedback concerning response accuracy was provided every 20 trials. After the experiment participants filled out a brief questionnaire about the experiment. Participants were asked to repeat the instructions that were given, what they thought the experiment was testing, and whether they were using any strategies. We also asked them if they noticed anything peculiar about the target presentation (i.e., target changed color or location), and if they noticed anything, when during the experiment they did.
\end{abstract}

\section{Results}

Incorrect responses $(2.55 \%$ of trials) and reaction times higher than $10,000 \mathrm{msec}(0.19 \%$ of trials $)$ were counted as errors and were excluded from the analyses. Trials in which the eyes moved away from the fixation point prior to the presentation of the first search display ( $4.34 \%$ of trials) were also counted as errors and were not analyzed further.

Figure 6 shows the RT distribution of the correct responses in the (A) standard search trials and (B) the contingent search trials. Figure 7 shows the normalized distributions of correct RT. The standard search trials replicated the results of Experiment 1 in that the distribution of responses following the second and subsequent looks was significantly different from the distribution following the first look $\left[\chi^{2}(9,1848)=143.70, p<.001\right.$, Cramer's $V=$ 0.279 ] (comparison across ten 100 -msec bins).

After one look, participants were able to correctly identify the target in $14 \%$ of trials in the standard search condition and $13 \%$ of trials in the contingent search condition. In this first epoch, most of the responses occurred in the second half of the distribution (in the standard search trials only $0.49 \%$ of responses in the first epoch was faster than $500 \mathrm{msec} ; 0.25 \%$ of responses were faster than $500 \mathrm{msec}$ in the contingent search trials). There was no significant difference between the response distribution found in the standard search condition as compared to the contingent search condition in the first epoch $\left[\chi^{2}(5,502)=2.56, p>.1\right.$, Cramer's $V=0.07]$ (comparison across six 100-msec bins).

There was a significant difference between the response distribution in the standard search trials compared to the contingent search in Epoch $2\left[\chi^{2}(9,2001)=178.67, p<\right.$ .01 , Cramer's $V=0.30$ ] (comparison across ten 100-msec bins). In the standard search condition, $25 \%$ of responses occurred following the second look. In contrast, $75 \%$ of all responses occurred following the gaze-contingent target presentation in the second look. In the second epoch, in the standard search trials, $47 \%$ of responses in this epoch occurred within the first $500 \mathrm{msec}$. In compari- 
A

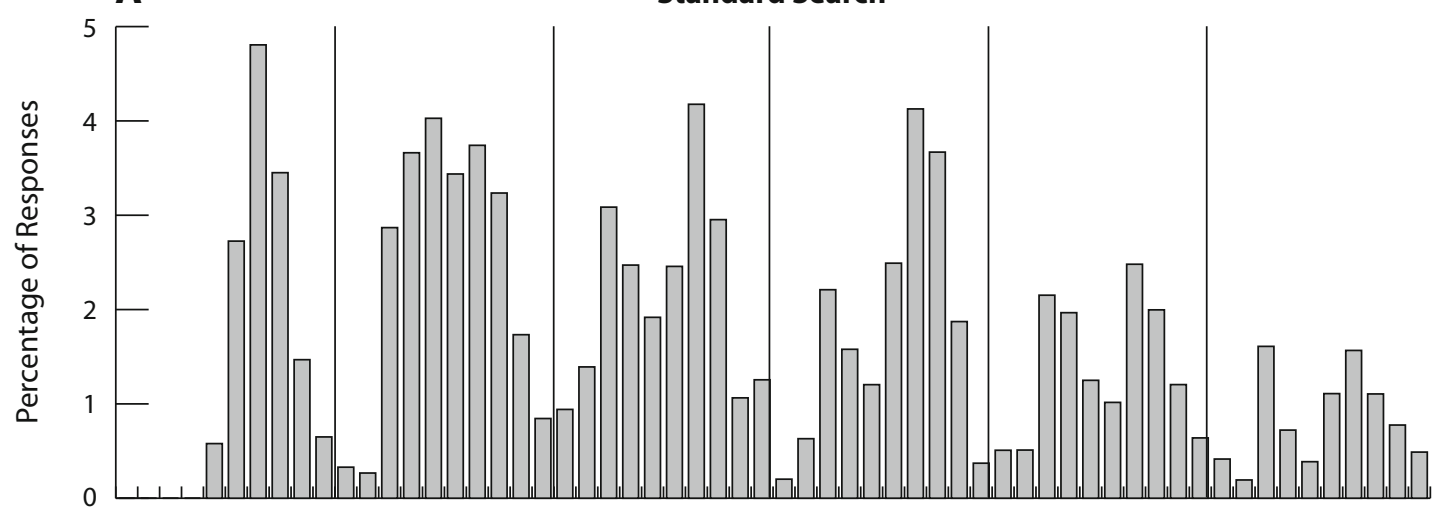

B

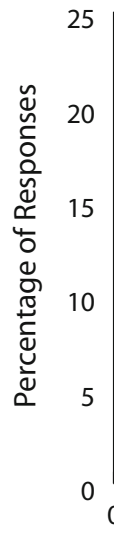

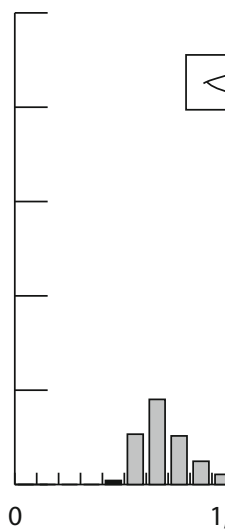

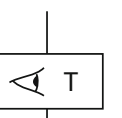

look

blank

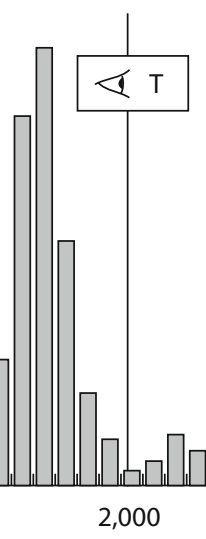

Contingent Search

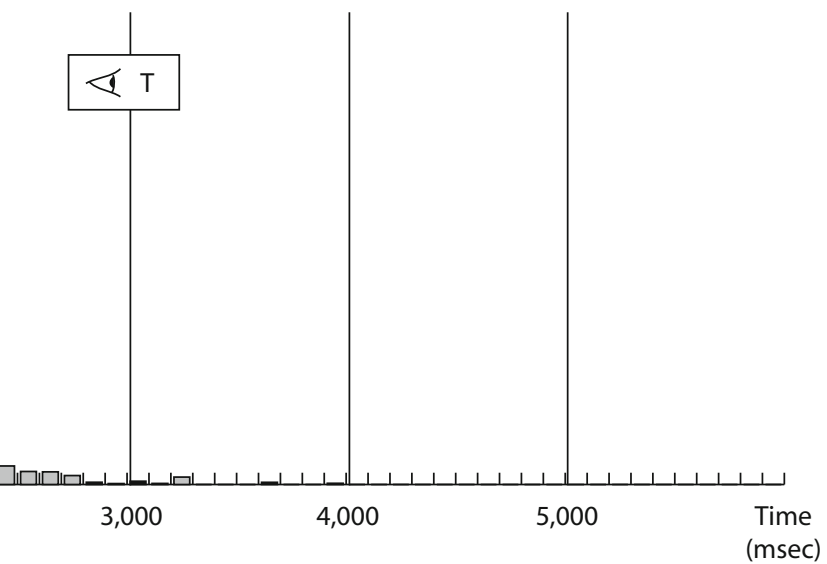

Figure 6. The distributions of correct response times (RT) in Experiment 2 for the standard noncontingent search trials in the control condition (A), and the gaze-contingent target presentation trials (B). Note that the scale on the vertical axis of the two histograms is not the same.
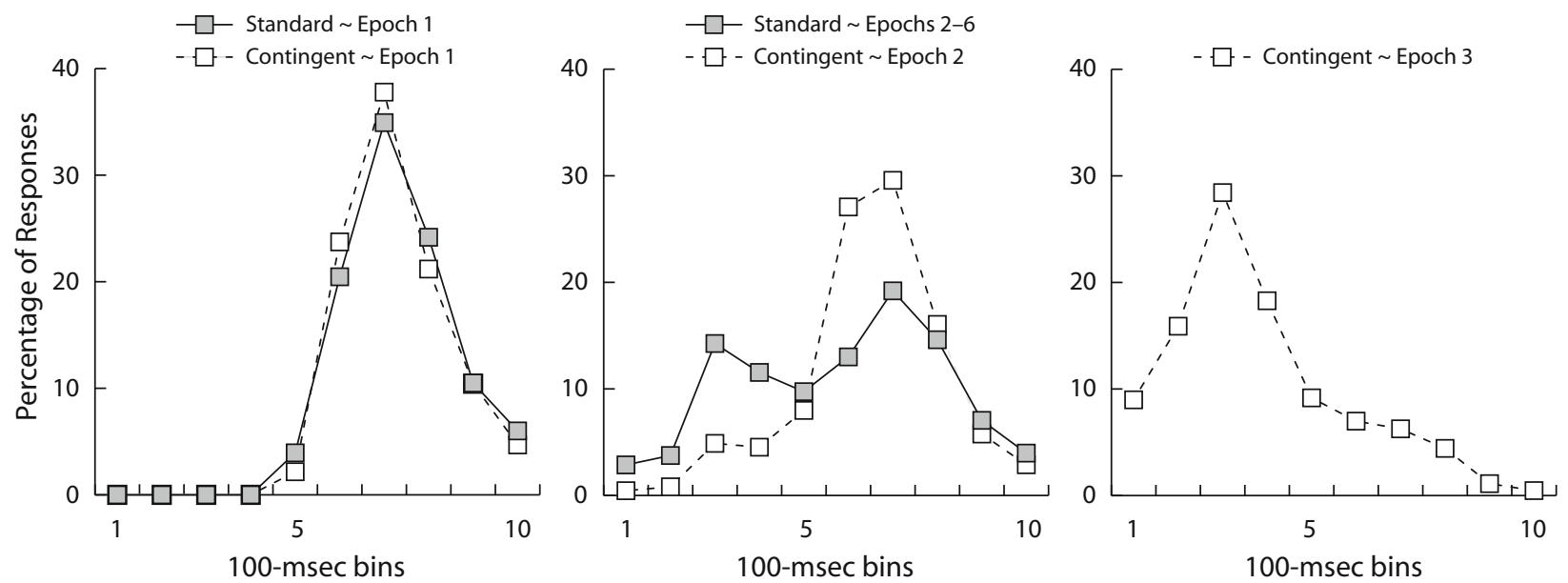

Figure 7. Normalized RT distributions for corrects responses in Experiment 2 for standard search and gaze-contingent presentation search. 
son only $18 \%$ of responses occurred within $500 \mathrm{msec}$ in the contingent search trials in this epoch. In this second epoch, average response times for responses made following a contingent trial $(1,604 \mathrm{msec})$ were significantly higher than for responses made in the standard search trials $(1,520 \mathrm{msec})[t(11)=4.69, p<.001]$. The likelihood of $R R$ responses following contingent presentation in the second epoch was decreased relative to the number of RR responses observed in the standard search trials.

We compared the distribution of responses in Epoch 3 of the standard search condition with those in the gazecontingent condition (i.e., responses following two gazecontingent looks). In the third epoch, $43 \%$ of the responses in the standard search trials occurred within the first $500 \mathrm{msec}$; in the contingent search trials, $79 \%$ of responses in the third epoch occurred within the first $500 \mathrm{msec}$. There was no significant difference between the distribution of responses that occurred within $500 \mathrm{msec}$ between the standard search trials and the contingent search trials $\left[\chi^{2}(4,320)=4.59, p>.1\right.$, Cramer's $V=0.12]$ (comparison across five 100 -msec bins). Rapid resumption of search occurred in the standard search condition in Epoch 3 as well as when the target was presented at eye fixation in two consecutive looks. Further, there was a significant increase in the percentage of RR responses from Epoch 2 to 3 in the gaze-contingent condition $\left[\chi^{2}(4,431)=68.31, p<.001\right.$, Cramer's $\left.V=0.398\right]$ (comparison across five 100-msec bins).

We checked to see if participants who were aware of the gaze-contingent target presentation responded differently than those who had not noticed the gaze-contingent target presentation. In the questionnaire that was answered by the participants following the experiment, 6 observers reported they had noticed nothing peculiar about the target presentation; 6 observers reported that sometimes during the experiment, the target was conspicuously often presented close to where they were looking. We compared the frequency of RR responses and NS responses elicited following the gaze-contingent look in the aware group to the not-aware group. No significant differences were found between the two response distributions that were observed in the two groups $\left[\chi^{2}(1,1630)=0.373, p>.1\right.$, Cramer's $V=0.015]$ (comparison across two bins).

\section{Discussion}

Experiment 2 yielded three major results. First, the results of Experiment 1 were replicated in the standard search condition in Experiment 2, showing that people were able to complete a search much faster if they had a prior look at the display. Second, presenting the target at eye fixation in the second look following the interruption of search not only did not increase the likelihood of rapid resumption responses: It decreased the likelihood. Third, when the target was presented at eye fixation in two consecutive looks (i.e., in the third epoch) virtually all responses were in the rapid resumption window of $0-500$ msec. $^{1}$

Presenting the target at eye fixation sharply increased the likelihood of successful target identification within the next second. However, in contrast to the standard pre- sentation trials, the gaze-contingent target presentation drastically reduced the likelihood of a response within the rapid resumption window $(0-500 \mathrm{msec})$. Most of the responses that were triggered following the gaze-contingent second look happened in the second half in this epoch: Participants were slower to respond to the target when it was presented at eye fixation. In other words, looking only at the responses elicited in the second epoch, participants were relatively quicker to respond to the target when they searched for the target autonomously in the standard condition $(1,520 \mathrm{msec})$, than when the target was offered to them at the center of gaze in the gaze-contingent condition $(1,604 \mathrm{msec})$. On gaze-contingent trials, even though participants did not have to initiate a new search because the target was fixated and correctly identified; search speed was less optimal.

The position that rapid resumption may crucially depend on eye position in the final look only, predicted that participants should have performed equally well or better when the target was presented to them at eye fixation as compared to somewhere else. When the target is presented at the center of gaze, performance should have been comparable to a condition where the target is the only element present in the display. As Lleras et al. (2005) have shown, in a case where only the target was presented without any distractors, the peak of the RT distribution was similar to the latency of the first peak in a distribution when RR of search occurs. However, the distribution of responses that were observed following gaze-contingent target presentation was unlike the first peak in the RR response distribution. The distribution of responses to a target presented at the center of gaze was instead similar to the distribution of responses in the first epoch following the initial look at the search display (or equivalently, the second peak in the RR distribution). Thus, even though participants were looking directly at the target, their speed of response was as if they had just started a new search.

The results of Experiment 2 are in line with a perceptual hypothesis account of guidance in visual search. The slow responding on gaze-contingent trials can be explained by the existence of a mismatch between the incoming information and the perceptual hypothesis created in the first look. On gaze-contingent trials it was highly likely that the target was no longer at its previous location. Therefore, the incoming sensory information no longer matched the preprocessed information and confirmation of the perceptual hypothesis was not possible. This meant that a new hypothesis about the target needed to be created and confirmed, leading to the overall slowing in RT when the target is presented at the center of gaze. Another way to put this is that the trace of the target in another location formed on an initial look is sufficiently strong to impair identification of the target, even when this target is now presented at eye fixation.

The results of Experiment 2 are clear in showing that rapid resumption is not predicted by eye position alone. If it were, we would have found an increase in the percentage of rapid responses when the target was presented at eye fixation. Thus, rapid resumption is not an artifact of eye movements. Yet one could argue that presenting a target at 
eye fixation in one half of all trials may have encouraged the use of artificial search strategies. Even though the contingent and noncontingent trials were intermixed, it could have been the case that observers were using a different strategy on gaze-contingent than on noncontingent trials. In Experiment 3, gaze-contingent targets were presented in only one randomly determined look during each trial in order to limit the possibility of artificial search strategies influencing the results.

\section{EXPERIMENT 3 Infrequent Gaze-Contingent Presentations}

The target was presented to the fovea in either the second, third, or fourth look in a given trial. In one fourth of the trials no gaze-contingent programming was applied, and thus these trials were similar to the search trials presented in Experiment 1. Participants were not restricted to respond following a particular look, but similarly to Experiment 1 and 2 , responded as soon as they had identified the color of the target. As a consequence of this design, it was possible that observers responded to the identity of the target before gaze-contingent presentation was employed. For example, if the target was going to be presented at eye fixation in the third look, observers could have already responded following the first or second look. In turn, the overall percentage of gaze-contingent target presentation was lower than in Experiment 2. Gaze-contingent presentation was therefore better concealed from participants in Experiment 3.

\section{Method}

Participants. Fourteen students of the University of British Columbia participated for course-credit in one 60-min session. All reported having normal or corrected-to-normal vision. Due to poor calibration in one participant and the loss of one block of data of another participant, the data of 2 participants were omitted from the analysis resulting in a total of 12 participants.

Apparatus and Stimuli. The apparatus and stimuli were identical to that in Experiment 1.

Design and Procedure. The design and procedures were similar to those of Experiment 2, except for that the target was presented at eye fixation only in one prespecified look. The target was present in every look, but was presented at eye fixation either in the second look ( $25 \%$ of all trials), the third look ( $25 \%$ of trials), or the fourth look ( $25 \%$ of trials). In $25 \%$ of the trials, no contingent eye programming was employed and these trials thus constituted as standard search trials (i.e., identical to the search trials in Experiment 1). The target was displaced only once such that the search display presented in the looks that followed the contingent presentation look was identical to the display generated in the gaze-contingent look.

\section{Results}

Incorrect responses ( $4.19 \%$ of trials) and reaction times higher than $10,000 \mathrm{msec}(0.44 \%$ of trials $)$ were counted as errors and were excluded from the analyses. Trials in which the eyes moved away from the fixation point prior to the presentation of the first search display $(4.93 \%$ of trials) were also counted as errors and were not analyzed further.

Figure 8 shows the normalized RT distribution of the correct responses in (A) the standard search condition and (B) the gaze-contingent presentation conditions. The standard search trials replicated the finding of rapid resumption in Epochs 2 and beyond. The RT distributions following the second and subsequent looks were significantly different from the RT distribution for the first look $\left[\chi^{2}(9,883)=70.39, p<.001\right.$, Cramer's $\left.V=0.282\right]$ (comparison across ten 100-msec bins).

In the first epoch, the majority of the responses occurred $500 \mathrm{msec}$ after response onset. No significant differences were found in response distribution between the different types of presentation conditions in this first epoch (i.e., standard search, contingent target presentation in second, third, or fourth look) $\left[\chi^{2}(15,582)=7.77, p>.1\right.$, Cramer's $V=0.07]$ (comparison across six 100-msec bins). Note that in the contingent presentation conditions, contingent target presentation was initiated in the second and subsequent looks only. As a result, the distribution obtained in the first epoch all represent noncontingent search, therefore, it is not surprising there is no significant difference in response-distribution between the different conditions in the first epoch.

To check whether participants were responding in an identical manner up until the critical gaze-contingent look, the nongaze contingent second and subsequent looks in the different search conditions were compared. In gaze-contingent search conditions (i.e., when the target was presented at eye fixation in the third look or in the fourth look) looks preceding the prespecified contingent look also constituted noncontingent presentation searches. No significant differences were found between the response distributions obtained in noncontingent second epochs (i.e., standard search condition, gaze-contingent target presentation in the third look, and the fourth look) $\left[\chi^{2}(18,698)=21.97, p>.1\right.$, Cramer's $\left.V=0.13\right]$ (comparison across ten 100-msec bins). Also, no differences were found between the response distributions obtained in the noncontingent third epoch (i.e., standard search condition vs. gaze-contingent target presentation in the fourth look) $\left[\chi^{2}(9,376)=10.33, p>.1\right.$, Cramer's $\left.V=0.17\right]$ (comparison across ten 100-msec bins). Until at least the critical gaze-contingent look, observers were responding in an identical manner to the standard trials as the gazecontingent trials.

Finally, RT distributions following the critical gazecontingent presentation (in second, third, or fourth look) were compared. No significant differences $\left[\chi^{2}(18,1749)=\right.$ $18.72, p>.1$, Cramer's $V=0.07]$ were found across the three gaze-contingent conditions. Regardless of whether the target was presented contingent to gaze in the second, third, or fourth look, the distributions were alike.

We checked to see if participants that were aware of the gaze-contingent presentation responded differently than the observers who were not. In the questionnaire that was answered by the participants following the experiment, 5 observers reported they had noticed nothing peculiar about the target-presentation; 7 observers reported that sometimes during the experiment, the target was conspicuously often presented close to where they were looking. We compared the frequency of RR and NS responses elicited following the gaze-contingent looks 

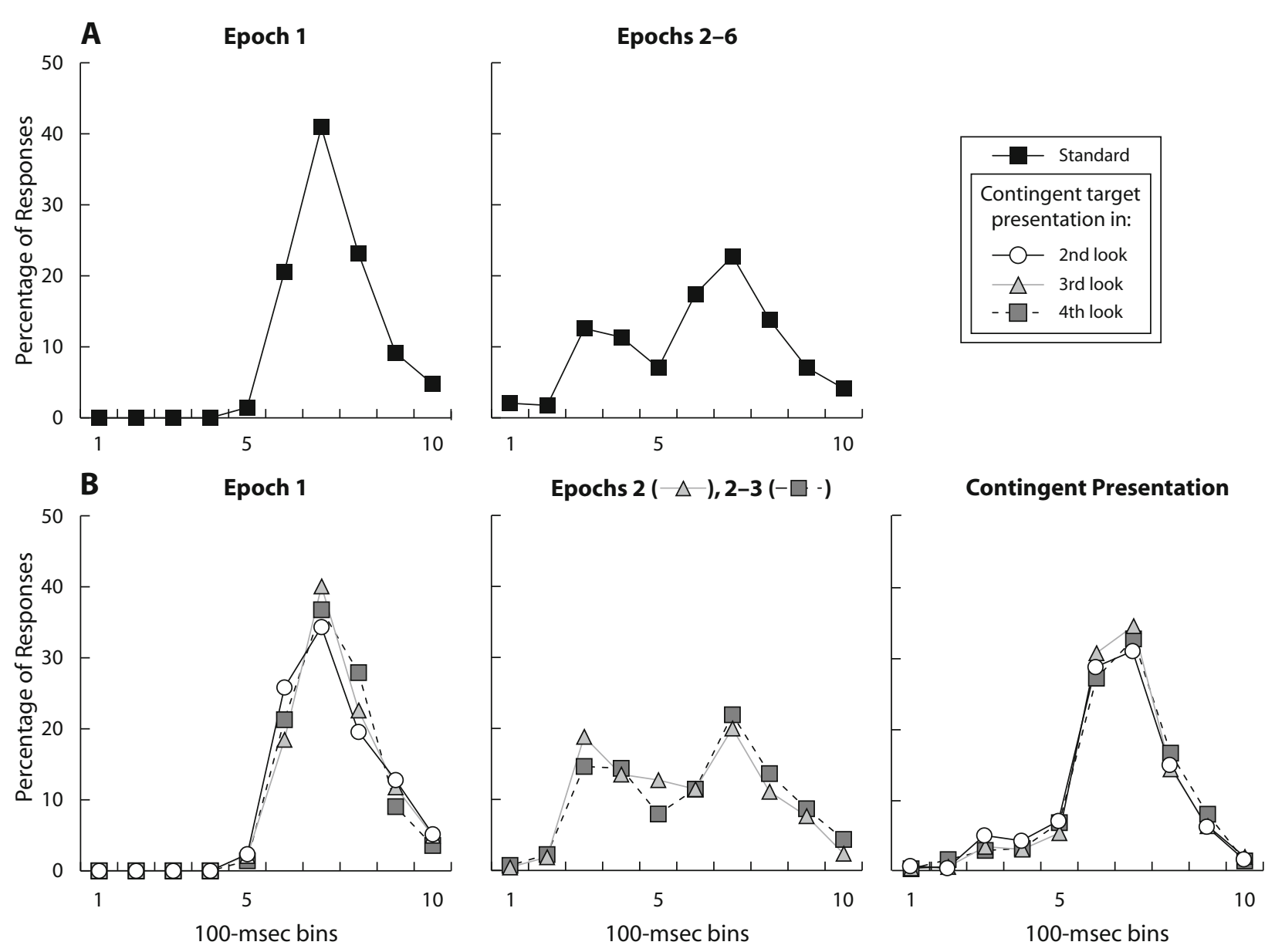

Figure 8. The normalized RT distributions of the correct responses in Experiment 3 for the standard search condition (A) and the gaze-contingent presentation in the $2 \mathrm{nd}, 3 \mathrm{rd}$, or 4 th look (B).

in the aware group and the not-aware group. No significant differences were found between the two groups following gaze-contingent presentation in the second look $\left[\chi^{2}(1,783)=0.194, p>.1\right.$, Cramer's $\left.V=0.016\right]$, the third look $\left[\chi^{2}(1,582)=1.077, p>.1\right.$, Cramer's $\left.V=0.043\right]$, or the fourth look $\left[\chi^{2}(1,384)=1.321, p>.1\right.$, Cramer's $V=$ $0.059]$ (all comparisons are across two bins).

\section{Discussion}

As in Experiment 2, presenting the target to the fovea following the interruption of search did not increase the percentage of rapid resumption responses. Regardless of the specific look (i.e., second, third, or fourth) in which the target was presented to the fovea, the percentage of rapid responses decreased with gaze-contingent programming.

Because of the concern raised in Experiment 2 about possible strategic differences between gaze-contingent and standard search trials, it is important to note that the RT distributions elicited during trials in which the target eventually was presented at eye fixation, were identical to the RT distribution found in the standard search condition. Finding rapid resumption of search on looks prior to gaze-contingent target presentations suggests that until at least the critical gaze-contingent look, observers were responding in an identical manner to the standard trials as and the gaze-contingent trials.

\section{GENERAL DISCUSSION}

Rapid resumption refers to the finding that participants can complete an interrupted search more quickly than a new search. But is this benefit indicative of target preprocessing in the first glance or simply a fortuitous high-resolution view of the target when the search display reappears after an interruption? This study used gazecontingent display techniques to pit the benefits of having a foveal view of the target (i.e., a high-resolution spatial and color representation) against the costs of having the target change its location from one look to the next (i.e., seeing a target in a different location than the one expected based on a previous look). The results clearly show that the benefits of a foveal view did not overcome the costs of having the new target location violate the memory of the target in the previous location.

Experiment 1 replicated the rapid resumption effect while eye movements were passively recorded during an interrupted search task. The data revealed that the distance 
from the fovea to the target was shorter on trials leading to rapid resumption than on trials leading to normal search responses. Moreover, this difference in target proximity between the two types of responses was most pronounced on the next-to-last look before making the response, hinting at the importance of some form of memory for the target from one look to the next. Experiments 2 and 3 used a method of gaze-contingent target presentation to test whether eye position alone was the critical factor in rapid resumption. The results showed that rapid resumption was not predicted by eye position in the final look. Presenting the target directly to the center of gaze on some trials had the effect of sharply increasing the overall success of search during the next second $(0-1,000 \mathrm{msec})$, but at the same time, it sharply reduced the likelihood of a response within the rapid resumption window $(0-500 \mathrm{msec})$. In other words, when the target was moved to the fovea on the reappearance of an interrupted search display, target identification was highly likely but significantly slower than if the target had been left where it was.

These results are conclusive in showing that eye position alone does not guarantee rapid resumption of visual search. However, this does not mean that eye position is independent of the perceptual hypothesis formed in the first look. The passive recordings of eye position in Experiment 1 indicated that rapid resumption could be predicted by eye position in the next-to-last look. This suggests that once the eyes are located close enough to the target so that preprocessing of the search display includes a perceptual hypothesis about the target only one subsequent look is required to confirm the hypothesis.

\section{Interplay of Memory and Eye Movements During Visual Search}

The finding that people are able to rapidly resume an interrupted search is consistent with a role for memory in visual search (Lleras et al., 2005). Numerous previous studies have pointed to a close relationship between memory and attention (e.g., Awh \& Jonides, 2001; Awh, Jonides, \& Reuter-Lorenz, 1998; Awh, Sgarlata, \& Kliestik, 2005; Jiang et al., 2005; Kristjansson, 2000; Norman, 1968), and between memory and eye movements (e.g., Brockmole \& Irwin, 2005; Dickinson \& Zelinsky, 2005; Downing, 2000; Henderson \& Hollingworth, 2003; Hollingworth \& Henderson, 2002; Houtkamp \& Roelfsema, 2006; Irwin \& Gordon, 1998; Lawrence et al., 2004; Lawrence, Myerson, Oonk, \& Abrams, 2001; Peterson et al., 2001; Postle et al., 2006; Theeuwes et al., 2005). This research has shown that the contents of visual working memory influences the guidance of selective attention (e.g., Awh et al., 1998; Downing, 2000; Irwin \& Gordon, 1998; Olivers, Meijer, \& Theeuwes, 2006) and the programming of eye movements (Theeuwes et al., 2005). For example, Awh et al. (1998) demonstrated that selective attention is directed toward locations held in working memory, such that participants identified objects reliably faster when they appeared at locations currently being maintained in working memory. Direct influences of memory on oculomotor programming have also been shown. When participants made eye movements to a target while maintaining another lo- cation in memory, the trajectories of the eye movements were biased away from the location in memory (Theeuwes et al., 2005).

Covert attention and eye movements also function to actively maintain spatial information in memory (see Awh et al., 1998). If participants are prevented from directing attention toward locations in working memory, there is a decrease in memory accuracy. Similarly, irrelevant eye movement programming interferes with spatial working memory (Hale, Myerson, Rhee, Weiss, \& Abrams, 1996; Lawrence et al., 2004; Lawrence et al., 2001; Pearson \& Sahraie, 2003; Postle et al., 2006), as do mere shifts of covert attention (Awh et al., 1998; Lawrence et al., 2001), though eye movements seem to interfere to a much greater extent (Lawrence et al., 2004). In summary, eye movements can be studied as a window into the contents of short-term memory, and because short-term memory guides attention, eye movements provide a window to the expectations derived from the contents of memory.

The present study adds to this literature in a several ways, using eye movements as a window on the ongoing processes involved in visual search. We began with two important assumptions about eye movements in visual search: (1) Eye movements are guided by peripheral preprocessing of a scene, and (2) the purpose of an eye movement is to obtain a high-resolution view of the target in order to accurately identify it. The gaze contingent target presentations in Experiments 2 and 3 clearly helped participants accomplish the second goal. However, these gaze contingent presentations also interfered with participants' ability to predict where the target would be from one glance to the next and thereby they were unable to benefit from the peripheral preprocessing of the display that would otherwise occur.

A related insight gained from the present study is that participants seem unaware of preprocessing that occurs during the eye movements made in visual search. This was seen in Experiment 1, where the measures of proximity of fovea to target and fixation duration were both more predictive in the next-to-last look than they were in the final look that occurred before the target was identified. Yet participants were unaware of these aspects of their eye gaze behavior. Presumably, if they had explicit knowledge of it they could have used it to respond before taking their final look. Consistent with this, Lleras et al. (2005, Experiment 5) showed that when a second look was not presented to participants, their subsequent responses were at chance in accuracy. We therefore interpret these eye movement predictors of rapid resumption responses as evidence that the system guiding the eyes has information about the target that is not available to the conscious contents of working memory.

The lack of awareness of target preprocessing was also evident in Experiments 2 and 3, where participants were asked directly whether they were aware that that target was gaze contingent on some trials. Some reported they were and some did not. The important result was that awareness played no measurable role in the distribution of correct responses over time. Rapid resumption occurred reliably when the target was in the same location for two 
or more looks in a row and it was greatly reduced when the target moved to the current location of the fovea just before a subsequent look. The fact that this occurred regardless of whether participants were aware of the gaze contingent presentations is further evidence of a dissociation between the guidance of search and conscious target identification.

This dissociation has been noted previously. For example, benefits of repeating specific display configurations in a search task (so-called contextual cuing) occur without awareness in participants (see Chun \& Jiang, 1998; Chun \& Nakayama, 2000). Recent results from change detection experiments also show that participants have no awareness of target preprocessing until the final look before they make a correct response (Fencsik, Horowitz, Flusberg, \& Wolfe, 2006; Wolfe, Horowitz, Fencsik, \& Flusberg, 2006). In our own studies involving interrupted search tasks, voluntary cuing of attention to likely target locations does not in itself lead to rapid resumption (Lleras et al., 2005).

\section{Eye Movements and Expectations in Gaze- Contingent Visual Search}

From the studies we have reviewed in the previous section, it is clear that eye movements and memory are mutually supportive of one another. These results help to make it clear that eye movements as such were not the cause of the reduction in rapid resumption responses on gaze contingent trials in Experiments 2 and 3. Indeed, without any eye movements, targets would rarely fall within the $3^{\circ}$ of the center of gaze that seems to be required to identify the targets in these experiments (Experiment 1).

It also appears that a short distance between the eye and the target is needed in the first place is to engage in sufficient preprocessing to allow the formation of a perceptual hypothesis regarding the target. Eye movements are critical to accomplishing this. Preprocessing of the display in the visual periphery ordinarily guides subsequent eye movements to get an even better view of the possible target. What causes the reduction in rapid resumption responses on gaze contingent trials, then, is the violation of the unconscious expectation that has been formed about a specific target location. This results in a mismatch between the content of a perceptual hypothesis stored in memory and the sensory information registered at the center of gaze.

The finding that rapid resumption of interrupted search is eliminated when the target position is changed, suggests that the perceptual hypothesis stored in memory includes information regarding the position of the target. This is in line with previous work demonstrating the importance of a stable display configuration for obtaining the rapid resumption effect (Lleras et al., 2005, 2007). When all search items, including the target, were randomly shuffled between looks in that study, no rapid resumption occurred. More recent experiments have shown that only changes made to task-relevant features of the target are able to eliminate RR; changes to task-irrelevant features do not eliminate RR (Lleras et al., 2007). For example, when the distractors were randomly shuffled between looks with the target remaining at the same location, rapid resumption was still observed. Lleras et al. (2007) concluded that rapid resumption is related to target-specific preprocessing and is only slightly affected by changes to nontarget item in the display. Following this logic, the results of the present study suggest that target position is a task-relevant feature and that it too is stored in the perceptual hypothesis.

It is important in this context to remind the reader that when the target was moved in the present study, participants were always left looking right at the target. No new eye movements were required to acquire any additional information about the target. Yet participants were still slower to respond to target identity when the target was presented at eye fixation after having been moved than when it remained further from the fovea but did not move.

In conclusion, rapid resumption of interrupted search is not explained by eye position in the final look prior to a correct response. In line with previous work, rapid resumption is best explained by preprocessing of targetrelevant features in the display. Eye movements appear to mediate target preprocessing that is crucial for rapid resumption of search. Accordingly, eye position in the nextto-last look best predicts the rapid resumption of search. We conclude that rather than depending on a high-quality single look at a search target, rapid resumption of search depends on two glances; a first glance in which a hypothesis is formed, and a second glance in which the hypothesis is confirmed.

\section{AUTHOR NOTE}

This research was supported by a Netherlands Organization for Scientific Research postdoctoral grant (NWO Talent) to W.v.Z., NSF Grant 0527361 to A.L., NSERC and SSHRC grants to A.K., and an NSERC discovery research grant to J.T.E. Correspondence concerning this article should be addressed to W. van Zoest, Department of Psychology, University of British Columbia, 2136 West Mall, Vancouver, BC, V6T 1Z4 Canada (e-mail: wieske@psych.ubc.ca).

\section{REFERENCES}

Awh, E., \& Jonides, J. (2001). Overlapping mechanisms of attention and spatial working memory. Trends in Cognitive Science, 5, 119126.

Awh, E., Jonides, J., \& Reuter-Lorenz, P. A. (1998). Rehearsal in spatial working memory. Journal of Experimental Psychology: Human Perception \& Performance, 24, 780-790.

Awh, E., Sgarlata, A. M., \& Kliestik, J. (2005). Resolving visual interference during covert spatial orienting: online attentional control through static records of prior visual experience. Journal of Experimental Psychology: General, 134, 192-206.

Beck, M. R., Peterson, M. S., \& Vomela, M. (2006). Memory for where, but not what, is used during visual search. Journal of Experimental Psychology: Human Perception \& Performance, 32, 235-250.

Brockmole, J. R., \& Henderson, J. M. (2006). Recognition and attention guidance during contextual cueing in real-world scenes: Evidence from eye movements. Quarterly Journal of Experimental Psychology, 59, 1177-1187.

Brockmole, J. R., \& Irwin, D. E. (2005). Eye movements and the integration of visual memory and visual perception. Perception \& Psychophysics, 67, 495-512.

Chun, M. M., \& JiAng, Y. (1998). Contextual cueing: Implicit learning and memory of visual context guides spatial attention. Cognitive Psychology, 36, 28-71. 
Chun, M. M., \& Jiang, Y. (2003). Implicit, long-term spatial contextual memory. Journal of Experimental Psychology: Learning, Memory, \& Cognition, 29, 224-234.

Chun, M. M., \& Nakayama, K. (2000). On the functional role of implicit visual memory for the adaptive deployment of attention across scenes. Visual Cognition, 7, 65-81.

Deubel, H., \& SchneIder, W. X. (1996). Saccade target selection and object recognition: Evidence for a common attentional mechanism. Vision Research, 36, 1827-1837.

Dickinson, C. A., \& Zelinsky, G. J. (2005). Marking rejected distractors: A gaze-contingent technique for measuring memory during search. Psychonomic Bulletin \& Review, 12, 1120-1126.

DownING, P. E. (2000). Interactions between visual working memory and selective attention. Psychological Science, 11, 467-473.

Fencsik, D. E., Horowitz, T. S., Flusberg, S. J., \& Wolfe, J. M. (2006, May). Change detection has no foresight: Measuring advanced knowledge of changes across displays. Poster presented at the annual meeting of the Vision Sciences Society, Sarasota, Florida.

Hale, S., Myerson, J., Rhee, S. H., Weiss, C. S., \& Abrams, R. A. (1996). Selective interference with the maintenance of location information in working memory. Neuropsychology, 10, 228-240.

Henderson, J. M., \& Hollingworth, A. (2003). Eye movements and visual memory: Detecting changes to saccade targets in scenes. Perception \& Psychophysics, 65, 58-71.

HofFman, J. E., \& Subramaniam, B. (1995). The role of visual attention in saccadic eye movements. Perception \& Psychophysics, 37, 787-795.

Hollingworth, A., \& Henderson, J. M. (2002). Accurate visual memory for previously attended objects in natural scenes. Journal of Experimental Psychology: Human Perception \& Performance, $\mathbf{2 8}$ $113-136$.

Horowitz, T. S., \& Wolfe, J. M. (1998). Visual search has no memory. Nature, 394, 575-577.

Horowitz, T. S., \& Wolfe, J. M. (2001). Search for multiple targets: Remember the targets, forget the search. Perception \& Psychophysics, 63, 272-285.

HoutKamp, R., \& Roelfsema, P. R. (2006). The effect of items in working memory on the deployment of attention and the eyes during visual search. Journal of Experimental Psychology: Human Perception \& Performance, 32, 423-442.

Irwin, D. E., \& Gordon, R. D. (1998). Eye movements, attention, and trans-saccadic memory. Visual Cognition, 5, 127-155.

JiAng, Y., Song, J. H., \& Rigas, A. (2005). High-capacity spatial contextual memory. Psychonomic Bulletin \& Review, 12, 524-529.

KLEIN, R. M., \& MacInNES, W. J. (1999). Inhibition of return is a foraging facilitator in visual search. Psychological Science, 10, 346-352.

Kowler, E., Anderson, E., Dosher, B., \& Blaser, E. (1995). The role of attention in the programming of saccades. Vision Research, 35, 1897-1916.

KRISTJAnsson, A. (2000). In search of remembrance: Evidence for memory in visual search. Psychological Science, 11, 328-332.

LaWrence, B. M., Myerson, J., \& Abrams, R. A. (2004). Interference with spatial working memory: An eye movement is more than a shift of attention. Psychonomic Bulletin \& Review, 11, 488-494.

Lawrence, B. M., Myerson, J., Oonk, H. M., \& Abrams, R. A. (2001). The effects of eye and limb movements on working memory. Memory, 9, 433-444.

Lleras, A., Rensink, R. A., \& EnNs, J. T. (2005). Rapid resumption of interrupted visual search: New insights on the interaction between vision and memory. Psychological Science, 16, 684-688.

Lleras, A., Rensink, R. A., \& Enns, J. T. (2007). Consequences of display changes during interrupted visual search: Rapid resumption is target specific. Perception \& Psychophysics, 69, 980-993.
McCarley, J. S., Wang, R. X. F., Kramer, A. F., Irwin, D. E., \& PeTERSON, M. S. (2003). How much memory does oculomotor search have? Psychological Science, 14, 422-426.

McPeek, R. M., Maljkovic, V., \& Nakayama, K. (1999). Saccades require focal attention and are facilitated by a short-term memory system. Vision Research, 39, 1555-1566.

Norman, D. A. (1968). Toward a theory of memory and attention. Psychological Review, 75, 522-536.

Он, S. H., \& Kıм, M. S. (2004). The role of spatial working memory in visual search efficiency. Psychonomic Bulletin \& Review, 11, 275281.

Olivers, C. N. L., Meijer, F., \& Theeuwes, J. (2006). Feature-based memory-driven attentional capture: Visual working memory content affects visual attention. Journal of Experimental Psychology: Human Perception \& Performance, 32, 1243-1265.

Pearson, D., \& Sahraie, A. (2003). Oculomotor control and the maintenance of spatially and temporally distributed events in visuo-spatial working memory. Quarterly Journal of Experimental Psychology, 56, 1089-1111.

Peterson, M. S., Kramer, A. F., Wang, R. F., Irwin, D. E., \& McCarLEY, J. S. (2001). Visual search has memory. Psychological Science, 12, 287-292.

Postle, B. R., Idzikowski, C., Sala, S. D., Logie, R. H., \& Baddeley, A. D. (2006). The selective disruption of spatial working memory by eye movements. Quarterly Journal of Experimental Psychology, 59, 100-120.

Schneider, W. X., \& Deubel, H. (1995). Visual attention and saccadic eye movements: Evidence for obligatory and selective spatial coupling. In J. M. Findlay, R. Walker, \& R. W. Kentridge (Eds.), Eye movement research: Mechanism, processes, and applications (pp. 317-324). Amsterdam: Elsevier.

ShePherd, M., Findley, J. M., \& Hockey, R. J. (1986). The relationship between eye movements and spatial attention. Quarterly Journal of Experimental Psychology, 38, 475-491.

Theeuwes, J., Olivers, C. N. L., \& Chizk, C. L. (2005). Remembering a location makes the eyes curve away. Psychological Science, 16, 196-199.

von Mühlenen, A., Müller, H. J., \& Müller, D. (2003). Sit-andwait strategies in dynamic visual search. Psychological Science, 14, 309-314.

Wolfe, J. M., Horowitz, T. S., FencsiK, D. E., \& Flusberg, S. J. (2006). Visual search has no foresight. Journal of Vision, 6, 788-788.

Woodman, G. F., Vogel, E. K., \& LucK, S. J. (2001). Visual search remains efficient when visual working memory is full. Psychological Science, 12, 219-224.

\section{NOTE}

1. It is difficult to know how stationary the eyes were (or alternatively how much they moved) on two successive gaze-contingent target presentations. If the eyes moved and rapid resumption still occurred, it would suggest that target preprocessing can be based on retinotopic coordinates. But if the eyes were stationary, it would suggest that target preprocessing was scene-based. This ambiguity is difficult to resolve in the present data because of the very small number of trials involving two successive gaze-contingent target presentations (only $9.2 \%$ of all trials: $7.4 \%$ RR and $1.8 \%$ NS responses) and thus will have to await a study specifically designed to examine this question.

(Manuscript received January 23, 2007, revision accepted for publication April 4, 2007.) 